\title{
Quality of life in children with infantile hemangioma: a case control study
}

\author{
Chuan Wang ${ }^{1}$, Yanan $\mathrm{Li}^{1}$, Bo Xiang ${ }^{1}$, Fei Xiong ${ }^{2}$, Kai $\mathrm{Li}^{3}$, Kaiying Yang ${ }^{1}$, Siyuan Chen ${ }^{4^{*}}$ and Yi $\mathrm{Ji}^{\text {* }^{*}}$
}

\begin{abstract}
Background: Infantile hemangioma $(\mathrm{IH})$ is the most common vascular tumor in children. It is controversial whether $\mathrm{H}$ s has effects on the quality of life (QOL) in patients of whom $\mathrm{H}$ poses no threat or potential for complication. Thus, we conducted this study to evaluate the q QOL in patients with $\mathrm{H}$ and find the predictors of poor QOL.

Methods: The PedsQL 4.0 Genetic Core Scales and the PedsQL family information form were administered to parents of children with $1 \mathrm{H}$ and healthy children both younger than 2-year-old. The quality-of-life instrument for $\mathbb{H}(\mathrm{IH}-\mathrm{Q} \mathrm{QL})$ and the PedsQL 4.0 family impact module were administered to parents of children with $\mathrm{H}$. We compared the PedsQL 4.0 Genetic Core Scales (GCIS) scores of the two groups. Multiple step-wise regression analysis was used to determine factors that influenced QOL in children with $\mathrm{IH}$ and their parents.
\end{abstract}

Results: Except for physical symptom, we found no significant difference in GCIS between patient group and healthy group $(P=0.409)$. The internal reliability of $\mathrm{H}-\mathrm{QO}$ was excellent with the Cronbach's alpha coefficient for summary scores being 0.76. Multiple step-wise regression analysis showed that the predictors of poor $\mathrm{HH}-\mathrm{QOL}$ total scores were hemangioma size, location, and mother's education level. The predictors of poor FIM total scores were hemangioma location and father's education level. The predictors of poor GCIS total scores were children's age, hemangioma location and father's education level.

Conclusion: The findings support the feasibility and reliability of the Chinese version of $\mathrm{H}-\mathrm{QOL}$ to evaluate the QOL in children with $\mathrm{H}$ and their parents. Hemangioma size, location and education level of mother are important impact factors for QOL in children with $\mathrm{IH}$ and their parents.

Keywords: Infantile hemangioma, Quality of life, QOL instrument for IH, Pediatric quality of life inventory, Hemangioma location

\section{Background}

Infantile hemangioma $(\mathrm{IH})$ is the most common vascular tumor in children, with an estimated prevalence of 5 to $10 \%$. IH usually presents at birth, develops rapidly in the first few months and involutes gradually at last. Depending on the appearance of IH and dictated by the depth, location, and stage of growth, the lesions are heterogeneous $[1-3]$. In most patients, the hemangioma lesions are small and pose no threat or potential for scarring and complication. However, in some cases, IHs can grow

\footnotetext{
*Correspondence: siy_chen@163.com; jijiyuanyuan@163.com

${ }^{4}$ Pediatric Intensive Care Unit, Department of Critical Care Medicine, West

China Hospital of Sichuan University, Chengdu, Sichuan Province, China

${ }^{1}$ Division of Oncology, Department of Pediatric Surgery, West China Hospital of Sichuan University, \#37 Guo-Xue-Xiang, Chengdu, Sichuan Province 610041, China

Full list of author information is available at the end of the article
}

dramatically, destroy tissues and organs, impair function, or even threaten the patients' lives [4]. Importantly, IHs are also able to cause physical distress and emotional concern to both children and their families, and all of these eventually influence quality of life (QOL) [5].

Improvement in QOL of patients and their families is one of the most significant outcomes of treatment in pediatric tumors. QOL of patients and their families is able to reflect the efficacy of treatment as well. Previously, investigators did not have validated diseasespecific instrument to evaluate the QOL in IH patients and their families. As results, the authors could not directly ask the patients and/or their parents about the influence of IHs. Studies using the generic QOL instruments have yielded conflicting results [6, 7]. By using a Dutch version of hemangioma-specific questionnaires, 
Hoornweg et al. demonstrated that most patients' QOL was not affected by IH [6]. However, the authors found considerable psychosocial impact of IH on patients, especially in those with complication or $\mathrm{IH}$ was visible located. Until recently, an English version of QOL instrument for IHs (IH-QOL) has been developed [8]. This instrument provides the required information account for the physical, emotional, social and cognitive development that takes place during the early critical period.

Until now, there is little information available on QOL in IH patients younger than 2 years old - when most of the IH growth has already occurred [9]. This is also the period that patients are most likely to undergo treatment, particularly in current 'propranolol era' [2]. It is still controversial whether IHs has effects on QOL in cases with small lesions. In addition, questions exist as to which factors are associated with QOL in $\mathrm{IH}$ patients and their parents.

The goal of the present study was to evaluate and analyze QOL in IH patients younger than 2 years old, with the aim to improve our understanding of the effects of $\mathrm{IH}$ on QOL in children and their parents.

\section{Methods}

\section{Participants and procedures}

This study was approved by the Ethics Committee of the West China Hospital of Sichuan University. All procedures followed the research protocols approved by West China Hospital of Sichuan University and West China Second University Hospital of Sichuan University and were conducted according to the Declaration of Helsinki. All patients were recruited from August 2015 and June 2016, at Department of Pediatric Surgery, West China Hospital of Sichuan University. The criteria for inclusion were as follows: 1) The patients were less than 2 years of age; 2) Patients were currently not received treatment; and 3) Consent of parents. The exclusion criteria were: 1) Patients were older than 2 year at the time of interview; 2) Patients had hemangioma-unrelated comorbid disease or major development disorders. Age and gender matched control subjects were healthy children aged 0 to 2 years. They were recruited from Department of Child Health, West China Second Hospital of Sichuan University, between August 2015 and June 2016.

Written informed consents were obtained from all children's parents. The location and size of hemangioma were noted. In the case of multiple IHs, only the clinically most important IH (typically the largest or visceral involvement) was documented. The parents completed the questionnaires during the patients' outpatient department visit. Questionnaires contained Chinese versions of IH-QOL and the Pediatric Quality of Life Inventory ${ }^{\mathrm{mm}}$ $\left(\right.$ PedsQL $\left.{ }^{\mathrm{Tm}}\right)$. PedsQL ${ }^{\mathrm{mm}}$ consisted of the PedsQL ${ }^{\mathrm{mm}}$ Family
Information Form (FIF), the pedsQL $\mathrm{L}^{\mathrm{tm}} 4.0$ Family Impact Module (FIM), the PedsQL ${ }^{\mathrm{Tm}} 4.0$ Generic Core Infant Scales (GCIS) 1-12 months and the PedsQL ${ }^{\mathrm{rm}} 4.0$ Generic Core Infant Scales 13-24 months. The parents of children in patient group were required to complete the IH-QOL, the PedsQL ${ }^{\mathrm{mm}}$ FIF, the pedsQL ${ }^{\mathrm{mm}}$ FIM and the PedsQL ${ }^{\mathrm{mm}} 4.0$ GCIS. The parents of children in healthy group were required to complete the PedsQL ${ }^{\mathrm{rm}}$ FIF and the PedsQL ${ }^{\mathrm{rm}}$ 4.0 GCIS. The investigators were trained by the project manager in order to guarantee the quality of the investigation. If the parents had questions on semantic or conceptual understanding, the investigators assisted parents to complete the questionnaires. Besides, the investigators were responsible to ensure there were no missing data in questionnaires.

\section{Instruments}

The PedsQL ${ }^{\mathrm{max}} 4.0$ GCIS 1-12 months and the PedsQL ${ }^{\mathrm{mm}}$ 4.0 GCIS 13-24 months are brief, parent-proxy-reported standardized questionnaires. They are widely used to assess QOL in pediatric patients [10]. The module encompasses 5 functional domains: physical functioning, physical symptom, emotional functioning, social functioning and cognitive functioning. The PedsQL ${ }^{\mathrm{ma}} 4.0$ GCIS $1-12$ months contains 36 items and the PedsQL ${ }^{\mathrm{mm}}$ 4.0 GCIS 13-24 months contains 45 items. The Chinese version of PedsQL ${ }^{\mathrm{mm}} 4.0$ GCIS has been demonstrated to have good internal consistency, as well as discriminant and construct validity for other disease [11, 12].

The PedsQL ${ }^{\mathrm{ma}}$ 4.0 FIF, which was cross-culturally adapted into Chinese, is aimed at collecting a child's basic information, including date of birth, gender and disease duration, as well as caregiver's basic information including marital status and education levels.

The PedsQL ${ }^{\mathrm{mi}}$ FIM, which was developed by Varni et al. [11-13], applies to measuring the impact of pediatric chronic disease on their family functioning. Chen et al. have translated it cross-culturally into Chinese version $[11,12,14]$. This instrument is composed of 9 dimensions (physical functioning, emotional functioning, social functioning, cognitive functioning, communication, worry, daily activities, family relationships and financial issues) and 37 items. The FIM can stand alone, or be integrated into the other measurement model, allowing an overall assessment of QOL of children and their parents.

The IH-QOL, which was developed by Sarah L Chamlin et al., is designed to measure the impact on $\mathrm{IH}$ patients and their parents [8]. This module consists of 4 domains (physical symptom of patient, social functioning of patient, social and psychological functioning of caregiver, and emotional functioning of caregiver) and 29 items. The Chinese Mandarin Version of IH-QOL was translated according to the standardized procedures and consisted of 
4 steps: forward translation (Chinese), backward translation (English), preliminary test and field test.

Likert-type scale responses are used in all questionnaires: $0=$ never a problem, $1=$ almost never a problem, $2=$ sometimes a problem, $3=$ often a problem and $4=$ almost always a problem. Scores of each item were linearly transformed into a 0 to 100 scale $(0=100,1=75$, $2=50,3=25,4=0)$.

\section{Statistical analysis}

All analyses were conducted using SPSS 22.0 for Windows (SPSS Inc., Chicago, USA). Chi-square $\left(x^{2}\right)$ tests were used to compare qualitative variables. Independent sample $t$-test was used to analyze the continuous variables. Pearson correlation coefficients were used to evaluate the scaling success, with value ranging 0.6 to 0.8 presenting strong correlation, and ranging 0.4 to 0.6 presenting moderate correlation. Internal consistency reliability of IH-QOL was determined by calculating Cronbach's alpha coefficient. For IH-QOL total score, Cronbach's alpha coefficient ranging from 0.7 to 0.8 presented good reliability, and from 0.65 to 0.7 presented moderate reliability. For subscales, Cronbach's alpha coefficient ranging from 0.7 to 0.8 presented good

Table 1 Demographics of patients and healthy children

\begin{tabular}{|c|c|c|c|}
\hline \multirow[t]{2}{*}{ Variables } & IH patients & Healthy children & \multirow[t]{2}{*}{$P$-values } \\
\hline & $n=217$ & $n=95$ & \\
\hline \multicolumn{4}{|l|}{ Children } \\
\hline Age $(m)^{a}$ & $6.59 \pm 5.15$ & $6.45 \pm 5.30$ & 0.827 \\
\hline Gender & & & 0.311 \\
\hline Male & 76 & 39 & \\
\hline Female & 141 & 56 & \\
\hline \multicolumn{4}{|l|}{ Parents } \\
\hline Gender & & & 0.805 \\
\hline Father & 121 & 51 & \\
\hline Mother & 96 & 44 & \\
\hline Marital status & & & 0.304 \\
\hline Married & 217 & 94 & \\
\hline Unmarried & 0 & 1 & \\
\hline Divorced & 0 & 0 & \\
\hline Mother's education level & & & 0.464 \\
\hline Lower education & 34 & 19 & \\
\hline Intermediate education & 111 & 42 & \\
\hline Higher education & 72 & 34 & \\
\hline Father's education level & & & 0.423 \\
\hline Lower education & 39 & 20 & \\
\hline Intermediate education & 106 & 41 & \\
\hline Higher education & 73 & 34 & \\
\hline
\end{tabular}

$n$ number of individuals, $m$ month

${ }^{a}$ Values are presented as mean (range) reliability, and from 0.6 to 0.7 presented moderate reliability. Multiple step-wise regression analyses were used to find out the main influencing factors for GCIS, FIM and IH-QOL total scores [15]. Statistical significance was set at $P<0.05$.

\section{Results}

Two hundred and seventeen children (76 male, 141 female) with IH were included. Ninety-five healthy children (39 male, 56 female) were selected as the healthy control group. Comparisons of demographic characteristics in two groups are listed in Table 1 . There were no significant differences in demographic characteristics between patient group and healthy children $(P>0.05)$. The clinical characteristics and demographic details of patient group are listed in Table 2. The craniofacial and neck area (109) was the dominant location, representing $50 \%$ of all $\mathrm{IHs}$, followed by the trunk (44), extremities (36), visceral involvement (16) and diaper area (12). Internal organ involvement in these children with $\mathrm{IH}$ contained 14 liver involvement, and 2 subglottie involvement. None of these 16 children developed complications.

Table 2 Clinical characteristics and demographic details of patients with infantile hemangiomas

\begin{tabular}{ll}
\hline Characteristics & $n$ \\
\hline Patients & \\
Child's age $(m)$ & 132 \\
$>0 ; \leq 6$ & 63 \\
$>6 ; \leq 12$ & 13 \\
$>12 ; \leq 18$ & 9 \\
$>18 ; \leq 24$ & \\
Infantile hemangiomas & \\
Location & 36 \\
Extremities & 44 \\
Trunk & 12 \\
Diaper are & 109 \\
Craniofacial and neck & 16 \\
Internal organs & \\
Number of lesions & \\
$\geq 1 ; \leq 2$ & 212 \\
$\geq 3 ; \leq 4$ & 3 \\
$\geq 5$ & 2 \\
Size (cm $\left.{ }^{2}\right)$ & 33 \\
$>0 ; \leq 2$ & 33 \\
$>2 ; \leq 4$ & 111 \\
$>4 ; \leq 6$ & 30 \\
$>6$ & \\
\hline$m$ month & \\
\hline & \\
& \\
&
\end{tabular}


Table 3 Scores of each instrument in patient group and healthy group

\begin{tabular}{|c|c|c|c|}
\hline Variables & Patient group (mean \pm SD) & healthy group (mean $\pm \mathrm{SD}$ ) & $P$-Values \\
\hline $\mathrm{IH}-\mathrm{QOL}$ & $84.79 \pm 12.75$ & N/A & N/A \\
\hline Physical symptom of patient & $90.13 \pm 14.72$ & N/A & N/A \\
\hline Social functioning of patient & $85.49 \pm 17.60$ & N/A & N/A \\
\hline Social and psychological functioning of caregiver & $89.03 \pm 15.50$ & N/A & N/A \\
\hline Emotional functioning of caregiver & $74.50 \pm 18.55$ & N/A & N/A \\
\hline PedsQL ${ }^{\text {TM }} 4.0$ Family Impact Module & $83.25 \pm 16.13$ & N/A & N/A \\
\hline Physical functioning & $82.66 \pm 19.34$ & N/A & N/A \\
\hline Emotional functioning & $83.55 \pm 21.02$ & N/A & N/A \\
\hline Social functioning & $85.54 \pm 17.68$ & N/A & N/A \\
\hline Cognitive functioning & $82.12 \pm 20.82$ & N/A & N/A \\
\hline Communication & $90.17 \pm 15.11$ & N/A & N/A \\
\hline Worry & $73.55 \pm 23.07$ & N/A & N/A \\
\hline Daily activities & $80.41 \pm 22.63$ & N/A & N/A \\
\hline Family relationships & $88.80 \pm 17.23$ & N/A & N/A \\
\hline Financial issues & $82.49 \pm 23.67$ & N/A & N/A \\
\hline PedsQL ${ }^{\text {TM }} 4.0$ Generic Core Infant Scales & $88.62 \pm 11.53$ & $89.68 \pm 6.16$ & 0.409 \\
\hline Physical functioning & $91.64 \pm 12.43$ & $91.41 \pm 9.01$ & 0.872 \\
\hline Physical symptom & $86.48 \pm 12.98$ & $90.29 \pm 10.78$ & 0.021 \\
\hline Emotional functioning & $84.29 \pm 15.70$ & $85.11 \pm 15.44$ & 0.734 \\
\hline Social functioning & $92.14 \pm 11.81$ & $91.95 \pm 12.03$ & 0.846 \\
\hline Cognitive functioning & $89.11 \pm 17.38$ & $89.63 \pm 13.92$ & 0.835 \\
\hline
\end{tabular}

${ }^{*}$ SD standard deviation, N/A not available

Scores of each instrument and each dimension are shown in Table 3. We found no significant difference in GCIS total scores between patient group and healthy group $(P=0.409)$. There were also no significant differences between two groups in scores of physical functioning $(P=0.872)$, emotional functioning $(P=0.734)$, social functioning $(P=0.846)$ and cognitive functioning $(P=0.835)$. However, there was significant difference in scores of physical symptom dimension between two groups $(P=0.021)$.

Table 4 demonstrates the internal reliability estimates of IH-QOL summary scale and subscales. The Cronbach's alpha coefficient for IH-QOL summary scores was 0.76 . The Cronbach's alpha coefficient for IH-QOL

Table 4 Cronbach's alpha coefficient for $\mathrm{H}_{-} \mathrm{QOL}$

\begin{tabular}{lll}
\hline Scale & $\begin{array}{l}\text { Item-summary } \\
\text { correlation }\end{array}$ & $\begin{array}{l}\text { Cronbach's alpha } \\
\text { coefficient }\end{array}$ \\
\hline Summary scale & N/A & 0.76 \\
Child physical symptoms & 0.489 & 0.75 \\
Child social interactions & 0.482 & 0.75 \\
Parent psychosocial functioning & 0.686 & 0.65 \\
Parent emotional functioning & 0.622 & 0.68
\end{tabular}

N/A not available subscale scores ranged from 0.65 to 0.75 . Item-summary correlation ranged from 0.482 to 0.686 , which meant strong correlation.

IH-QOL total score was moderately related to GCIS total score with Pearson correlation coefficient being $0.582(P<0.05)$ (Table 5). In addition, IH-QOL total score was strongly related to FIM total score with Pearson correlation coefficient being $0.713(P<0.05)$ (Table 6).

The outcomes of multiple step-wise regression analyses for IH-QOL total scores are listed in Table 7. We found the main influencing factors for IH-QOL total scores included hemangioma location, hemangioma size and mother's education level. For GCIS total scores, the main influencing factors included child's age, hemangioma location and father's education level (Table 8). For FIM total scores, the main influencing factors included hemangioma location and father's education level (Table 9).

\section{Discussion}

As experience treating IHs with $\beta$-blockers increases, a careful shift to more cosmetic indications is occurring. However, in spite of its efficacy, use of $\beta$-blockers has some risk [16-20]. This dilemma makes clinicians face new and difficult challenges when deciding whether or not to use $\beta$-blockers in small $\mathrm{IHs}$ when parents are 
Table 5 Pearson correlation coefficients between PedsQL ${ }^{\mathrm{TM}}$ Family Impact Module and $\mathrm{H}-\mathrm{QOL}{ }^{\mathrm{a}}$

\begin{tabular}{|c|c|c|c|c|c|}
\hline \multirow[t]{2}{*}{ PedsQL ${ }^{\text {TM }}$ Family Impact Module } & \multicolumn{5}{|l|}{$\mathrm{IH}-\mathrm{QOL}$} \\
\hline & $\begin{array}{l}\text { Physical symptom } \\
\text { of patient }\end{array}$ & $\begin{array}{l}\text { Social functioning } \\
\text { of patient }\end{array}$ & $\begin{array}{l}\text { Social and psychological functioning } \\
\text { of caregiver }\end{array}$ & $\begin{array}{l}\text { Emotional functioning } \\
\text { of caregiver }\end{array}$ & Summary score \\
\hline Physical functioning & 0.452 & 0.309 & 0.584 & 0.553 & 0.616 \\
\hline Emotional functioning & 0.460 & 0.347 & 0.621 & 0.644 & 0.675 \\
\hline Social functioning & 0.401 & 0.352 & 0.565 & 0.484 & 0.585 \\
\hline Cognitive functioning & 0.365 & 0.260 & 0.505 & 0.515 & 0.536 \\
\hline Communication & 0.313 & 0.326 & 0.535 & 0.502 & 0.548 \\
\hline Worry & 0.323 & 0.432 & 0.487 & 0.668 & 0.633 \\
\hline Daily activities & 0.376 & 0.270 & 0.514 & 0.523 & 0.548 \\
\hline Family relationships & 0.396 & 0.325 & 0.563 & 0.470 & 0.569 \\
\hline Financial issues & 0.341 & 0.245 & 0.401 & 0.411 & 0.455 \\
\hline Summary score & 0.377 & 0.335 & 0.634 & 0.667 & 0.713 \\
\hline
\end{tabular}

${ }^{a}$ Values denote Pearson correlation coefficients. The $P$ values of all coefficients above are less than 0.05

worried about their child's visible lesion, particularly present on the face. In this regard, QOL should be the important measurement to resolve the challenges and to evaluate the efficacy of treatment. Although several scoring systems for $\mathrm{IH}$ have been described over the years, there have been few studies describing QOL in IH patients and their parents $[21,22]$. In addition, only a few common instruments, like the PedsQL ${ }^{\mathrm{m}}$, could be used to assess the QOL in IH patients before IH-QOL developed. There is an emerging perspective that both generic and disease-specific instrument should be administered to $\mathrm{IH}$ patients and their families. For this reason, we chose to use both generic and disease-specific instrument in current study.

PedsQL ${ }^{2 m}$ is thought to be a reliable valid modular approach to evaluating QOL in children with or without disease [23, 24]. In the present study, we used the GCIS to evaluate the QOL in IH patients. Our results demonstrated that there was no significant difference in total score between $\mathrm{IH}$ patients and healthy children. These findings were inconsistent with report by Cohen-Barak et al. [7], who showed that $\mathrm{IH}$ patients and their parents even reported higher QOL than healthy children. In addition, we found physical symptom scores in patient group were significant lower than that of healthy children. One explanation for these obvious discrepancies is that Chinese parents seem to care more about the physical effects of $\mathrm{IH}$ on their children. Second, we have included patients with visceral IH. These patients can be associated with comorbid diseases and are more commonly to be managed aggressively with medical therapy $[4,25,26]$. Third, it might attribute to the marked age differences between two studies: in the present study, our children were too young to report on their own behalf. Only parent proxy-report was available. However, although children-self-reporting is important, perspective of parents also are critical. Furthermore, it is usually parents' perceptions of children's QOL that influences health care utilization [11, 27].

On the other hand, our data suggested that PedsQL ${ }^{\mathrm{m}}$ GCIS might not be able to accurately evaluate QOL in $\mathrm{IH}$ patients alone. Hence, disease-specific instrument should be used to evaluate the QOL in IH patients as well. Our study showed Chinese version of IH-QOL can be completed smoothly with few questions by most of parents. The internal reliability for the IH-QOL

Table 6 Pearson correlation coefficients between PedsQL ${ }^{\text {TM }} 4.0$ Generic Core Infant Scales and IH-QOL ${ }^{\text {a }}$

\begin{tabular}{|c|c|c|c|c|c|}
\hline \multirow[t]{2}{*}{ PedsQL ${ }^{\text {тм }} 4.0$ Generic Core Infant Scales } & \multicolumn{5}{|l|}{$\mathrm{IH}-\mathrm{QOL}$} \\
\hline & $\begin{array}{l}\text { Physical symptom } \\
\text { of patient }\end{array}$ & $\begin{array}{l}\text { Social functioning } \\
\text { of patient }\end{array}$ & $\begin{array}{l}\text { Social and psychological } \\
\text { functioning of caregiver }\end{array}$ & $\begin{array}{l}\text { Emotional functioning } \\
\text { of caregiver }\end{array}$ & Summary score \\
\hline Physical functioning & 0.451 & 0.323 & 0.355 & 0.388 & 0.498 \\
\hline Physical symptom & 0.426 & 0.265 & 0.359 & 0.525 & 0.523 \\
\hline Emotional functioning & 0.466 & 0.249 & 0.486 & 0.505 & 0.560 \\
\hline Social functioning & 0.261 & 0.234 & 0.323 & 0.304 & 0.371 \\
\hline Cognitive functioning & 0.338 & 0.201 & 0.418 & 0.347 & 0.427 \\
\hline Summary score & 0.471 & 0.308 & 0.479 & 0.504 & 0.582 \\
\hline
\end{tabular}

${ }^{a}$ Values denote Pearson correlation coefficients. The $P$ values of all coefficients above are less than 0.05 
Table 7 Factors influencing $\mathrm{IH}-\mathrm{QOL}$ total score in patients with infantile hemangiomas ${ }^{\text {a }}$

\begin{tabular}{|c|c|c|c|}
\hline Factors & Score $($ mean $\pm S D)$ & $\beta$-Values $(95 \% \mathrm{Cl})$ & $P$-Values \\
\hline Child's gender & & $-0.024(-4.111-2.8760)$ & 0.728 \\
\hline Female & $84.43 \pm 12.84$ & & \\
\hline Male & $85.47 \pm 12.62$ & & \\
\hline Child's age (month) & & $0.088(-0.115-0.541)$ & 0.202 \\
\hline$>0 ; \leq 6$ & $83.89 \pm 13.13$ & & \\
\hline$>6 ; \leq 12$ & $86.33 \pm 12.67$ & & \\
\hline$>12 ; \leq 18$ & $85.84 \pm 9.74$ & & \\
\hline$>18 ; \leq 24$ & $85.63 \pm 11.88$ & & \\
\hline Hemangioma location & & $0.148(0.034-1.487)$ & 0.04 \\
\hline Extremities & $87.67 \pm 9.57$ & & \\
\hline Trunk & $87.73 \pm 11.17$ & & \\
\hline Diaper area & $85.46 \pm 12.94$ & & \\
\hline Visceral involvement & $83.12 \pm 13.65$ & & \\
\hline Craniofacial and neck & $81.10 \pm 14.97$ & & \\
\hline Number of hemangioma & & $-0.091(-6.058-1.321)$ & 0.207 \\
\hline$\geq 1 ; \leq 2$ & $85.00 \pm 12.39$ & & \\
\hline$\geq 3 ; \leq 4$ & $81.24 \pm 18.44$ & & \\
\hline$\geq 5$ & $68.28 \pm 37.79$ & & \\
\hline Hemangioma size $\left(\mathrm{cm}^{2}\right)$ & & $-0.167(-0.563-0.062)$ & 0.015 \\
\hline$>0 ; \leq 2$ & $87.53 \pm 10.81$ & & \\
\hline$>2 ; \leq 4$ & $82.52 \pm 13.42$ & & \\
\hline$>4 ; \leq 6$ & $81.40 \pm 13.18$ & & \\
\hline$>6$ & $81.91 \pm 15.24$ & & \\
\hline Mother's education level & & $0.287(0.495-5.989)$ & 0.021 \\
\hline Lower education & $82.39 \pm 13.82$ & & \\
\hline Intermediate education & $84.59 \pm 13.48$ & & \\
\hline Higher education & $86.25 \pm 10.85$ & & \\
\hline Father's education level & & $-0.217(-4.974-0.203)$ & 0.071 \\
\hline Lower education & $83.21 \pm 14.00$ & & \\
\hline Intermediate education & $85.38 \pm 13.33$ & & \\
\hline Higher education & $84.73 \pm 11.23$ & & \\
\hline
\end{tabular}

summary and subscales scores was excellent, with a high degree of internal consistency among all item scores. In addition, our study found that IH-QOL was significantly correlated with GCIS and FIM. These findings are exciting, suggesting that these instruments can be used in combination. The data from these standardized instruments can provide more information than when they are used alone.

In keeping with the previous studies, our multiple stepwise regression analyses demonstrated that hemangioma location and size were related to QOL $[6,8]$. Remarkably, hemangioma location was the only factor influencing the total scores of all three instruments. We found that patient with $\mathrm{IH}$ in craniofacial and neck area had lower IH-QOL score than those with IH in trunk, diaper area or
Table 8 Factors influencing PedsQL ${ }^{\mathrm{TM}} 4.0$ Genetic Core Infant Scales total score in patients with infantile hemangiomas ${ }^{a}$

\begin{tabular}{llcc}
\hline Factors & Score $($ mean \pm SD) & $\beta$-Values $(95 \% \mathrm{Cl})$ & P-Values \\
\hline Child's gender & & $0.027(-2.956-4.263)$ & 0.358 \\
$\quad$ Female & $88.88 \pm 10.54$ & & \\
$\quad$ Male & $88.13 \pm 13.35$ & & \\
Child's age (month) & & $-0.156(-0.666-0.008)$ & 0.045 \\
$>0 ; \leq 6$ & $89.72 \pm 10.70$ & & \\
$>6 ; \leq 12$ & $87.86 \pm 11.74$ & & \\
$>12 ; \leq 18$ & $83.67 \pm 15.08$ & & \\
$>18 ; \leq 24$ & $85.36 \pm 15.23$ & & \\
Hemangioma location & & 0.025 \\
$\quad$ Extremities & $91.74 \pm 9.36$ & & \\
Trunk & $88.72 \pm 10.78$ & & \\
Visceral involvement & $88.42 \pm 11.30$ & & \\
Craniofacial and neck & $87.02 \pm 12.63$ & &
\end{tabular}

Number of hemangioma

$\begin{array}{ll}\geq 1 ; \leq 2 & 88.78 \pm 11.41 \\ \geq 3 ; \leq 4 & 89.11 \pm 18.00 \\ \geq 5 & 7469 \pm 9.63\end{array}$

Hemangioma size $\left(\mathrm{cm}^{2}\right)$

$0.062(-0.154-0.373) \quad 0.412$

$>0 ; \leq 2 \quad 89.02 \pm 11.58$

$>2 ; \leq 4 \quad 84.52 \pm 13.00$

$>4 ; \leq 6 \quad 91.44 \pm 11.16$

$\begin{array}{ll}>6 & 88.12 \pm 10.03\end{array}$

Mother's education level

Lower education $\quad 88.90 \pm 11.67$

Intermediate education $\quad 88.32 \pm 11.31$

Higher education $\quad 89.03 \pm 12.06$

Father's education level

$-0.275(-5.392-0.074) \quad 0.044$

Lower education $\quad 90.46 \pm 10.72$

Intermediate education $\quad 88.07 \pm 11.73$

Higher education $\quad 88.36 \pm 11.80$

${ }^{a}$ Multiple step-wise regression analyses were used to find out the main risk factors

extremities. This finding is not surprising given craniofacial and neck hemangiomas are visible and carry a high risk of residua scar than in other sites [28]. Many craniofacial and neck lesions can leave residual scars, which may have life-long effects [29]. In addition, we found that when hemangioma size was $>2 \mathrm{~cm}^{2}$, the IH-QOL total score decreased significantly. Therefore, for craniofacial and neck hemangioms with size $>2 \mathrm{~cm}^{2}$, early intervention may be justified to potentially arrest the growth of the lesion, and avoid psychosocial concerns [30]. The introduction of relatively safer topical agents (e.g., timolol) now allows earlier and easier intervention in appropriate cases [31-33].

It is noteworthy that parents with higher education level reported significantly higher QOL values. 
Table 9 Factors influencing PedsQL Family Impact Module total score in patients with infantile hemangiomas ${ }^{a}$

\begin{tabular}{|c|c|c|c|}
\hline Factors & Score (mean $\pm S D$ ) & $\beta$-Values $(95 \% \mathrm{Cl})$ & $P$-Values \\
\hline Child's gender & & $0.032(-0.3445-5.582)$ & 0.641 \\
\hline Female & $83.42 \pm 15.96$ & & \\
\hline Male & $82.79 \pm 16.48$ & & \\
\hline Child's age (month) & & $-0.036(-0.537-0.312)$ & 0.602 \\
\hline$>0 ; \leq 6$ & $83.52 \pm 16.93$ & & \\
\hline$>6 ; \leq 12$ & $83.28 \pm 14.95$ & & \\
\hline$>12 ; \leq 18$ & $82.73 \pm 12.32$ & & \\
\hline$>18 ; \leq 24$ & $79.64 \pm 18.66$ & & \\
\hline Hemangioma location & & $0.155(0.08-1.959)$ & 0.033 \\
\hline Extremities & $84.49 \pm 20.13$ & & \\
\hline Trunk & $83.88 \pm 19.23$ & & \\
\hline Visceral involvement & $83.74 \pm 16.41$ & & \\
\hline Craniofacial and neck & $81.82 \pm 15.72$ & & \\
\hline Number of hemangioma & & $-0.121(-8.842-0.693)$ & 0.094 \\
\hline$\geq 1 ; \leq 2$ & $83.50 \pm 16.00$ & & \\
\hline$\geq 3 ; \leq 4$ & $77.69 \pm 18.48$ & & \\
\hline$\geq 5$ & $65.26 \pm 27.33$ & & \\
\hline Hemangioma size $\left(\mathrm{cm}^{2}\right)$ & & $-0.114(-0.596-0.051)$ & 0.098 \\
\hline$>0 ; \leq 2$ & $86.42 \pm 13.00$ & & \\
\hline$>2 ; \leq 4$ & $79.11 \pm 17.61$ & & \\
\hline$>4 ; \leq 6$ & $84.19 \pm 15.01$ & & \\
\hline$>6$ & $77.25 \pm 20.82$ & & \\
\hline Mother's education level & & $0.227(-0.251-6.849)$ & 0.068 \\
\hline Lower education & $83.34 \pm 15.92$ & & \\
\hline Intermediate education & $82.53 \pm 16.93$ & & \\
\hline Higher education & $84.28 \pm 14.95$ & & \\
\hline Father's education level & & $-0.249(-6.850-0.160)$ & 0.040 \\
\hline Lower education & $85.19 \pm 14.59$ & & \\
\hline Intermediate education & $83.22 \pm 15.98$ & & \\
\hline Higher education & $82.32 \pm 17.18$ & & \\
\hline
\end{tabular}

${ }^{a}$ Multiple step-wise regression analyses were used to find out the main risk factors

Currently, accurate information for $\mathrm{IH}$ is disseminated widely via the Internet. Conceptually, parents with higher education levels may spend more time learning hemangioma characteristics by themselves. This finding is interesting, indicating that parents who worry about the QOL of their child can be reassured. In contrast, parents with lower education levels may have poor knowledge of $\mathrm{IH}$. This in turn, causes the heightened anxiety even for those IHs that are unlikely to cause complication or leave scarring. On the other hand, clinician may wish to counsel the parents regarding the changes of IH, such as rapid growth, infection or ulceration, and to establish with the parents a means to see the child on short notice if such changes are observed $[30,34]$. Furthermore, parental attitudes and beliefs are critical factors in treatment selection, more so in elective cases [2]. Thus, parental education on IH will not only directly improve the QOL, but may also indirectly improve QOL by preventing functional and/or cosmetic complications via early referral and timely intervention during the 'watchful waiting' period.

\section{Conclusion}

In conclusion, this study emphasizes that $\mathrm{IH}$ can influence the QOL in young patients and their parents. Our results demonstrate that PedsQL GCIS may not be sufficient to evaluate QOL in children with $\mathrm{IH}$ alone. IHQOL, with excellent internal reliability, is significantly associated with the PedsQL GCIS and FIM. In addition, our study provides novel findings that children's age, hemangioma location and size, and parents' education level are important risk factors for poor QOL in patients and their parents.

Abbreviations

FIF: The PedsQL ${ }^{\text {TM }}$ family information form; FIM: The pedsQL ${ }^{\text {TM }} 4.0$ family impact module; GCIS: The PedsQL 4.0 genetic core scales; IH: Infantile hemangioma; $\mathrm{HH}-\mathrm{QOL}$ : The quality-of-life instrument for $\mathrm{HH}^{\mathrm{H}}$ PedsQL ${ }^{\mathrm{TM}}$ : The pediatric quality of life inventory ${ }^{\mathrm{TM}}$; QOL: Quality of life

\section{Acknowledgements}

Not applicable.

\section{Funding}

This work was supported at collection, analysis, and interpretation of data and in writing the manuscript stages by grants from the National Natural Science Foundation of China (81401606 and 81400862), and the Science Foundation for Excellent Youth Scholars of Sichuan University (2015SU04A15).

\section{Availability of data and materials}

The datasets used and analysed during the current study are available from the corresponding author on reasonable request.

\section{Authors' contributions}

SYC and YJ contributed to the design of the study. CW and YJ reviewed the data, interpreted the statistical analysis and drafted the manuscript. CW, YNL, $B X, F X, K Y Y$ and YJ performed the experiments. CW analyzed the data. All of the authors read and approved the final manuscript.

\section{Ethics approval and consent to participate}

This study was approved by the Ethics Committee of the West China Hospital of Sichuan University and West China Second University Hospital of Sichuan University. All procedures followed the research protocols approved by West China Hospital of Sichuan University and West China Second University Hospital of Sichuan University and conducted according to the Declaration of Helsinki. Written informed consents were obtained from all children's parents.

\section{Consent for publication}

All children's parents had provided their consent regarding the publication of this manuscript.

\section{Competing interests}

The authors declare that they have no competing interests.

\section{Publisher's Note}

Springer Nature remains neutral with regard to jurisdictional claims in published maps and institutional affiliations. 


\section{Author details}

Division of Oncology, Department of Pediatric Surgery, West China Hospital of Sichuan University, \#37 Guo-Xue-Xiang, Chengdu, Sichuan Province 610041, China. ${ }^{2}$ Department of Child Health, West China Second University Hospital, Sichuan University, Sichuan Province, Chengdu, China. ${ }^{3}$ Division of Oncology, Department of Pediatric Surgery, Children's Hospital of Fudan University, Shanghai, China. ${ }^{4}$ Pediatric Intensive Care Unit, Department of Critical Care Medicine, West China Hospital of Sichuan University, Chengdu, Sichuan Province, China.

Received: 20 March 2017 Accepted: 28 September 2017 Published online: 16 November 2017

\section{References}

1. Munden A, Butschek R, Tom WL, Marshall JS, Poeltler DM, Krohne SE, et al. Prospective study of infantile haemangiomas: incidence, clinical characteristics and association with placental anomalies. Br J Dermatol. 2014;170:907-13.

2. Darrow DH, Greene AK, Mancini AJ, Nopper AJ. Diagnosis and management of infantile hemangioma. Pediatrics. 2015;136:e1060-104.

3. Drolet BA, Esterly NB, Frieden IJ. Hemangiomas in children. N Engl J Med. 1999:341:173-81

4. Ji Y, Chen S, Xiang B, Xu Z, Jiang X, Liu X, et al. Clinical features and management of multifocal hepatic hemangiomas in children: a retrospective study. Sci Rep. 2016;6:31744.

5. Zweegers J, van der Vleuten CJ. The psychosocial impact of an infantile haemangioma on children and their parents. Arch Dis Child. 2012;97:922-6.

6. Hoornweg MJ, Grootenhuis MA, van der Horst CM. Health-related quality of life and impact of haemangiomas on children and their parents. J Plast Reconstr Aesthet Surg. 2009;62:1265-71.

7. Cohen-Barak E, Rozenman D, Shani Adir A. Infantile haemangiomas and quality of life. Arch Dis Child. 2013:98:676-9.

8. Chamlin SL, Mancini AJ, Lai JS, Beaumont JL, Cella D, Adams D, et al. Development and validation of a quality-of-life instrument for infantile hemangiomas. J Invest Dermatol. 2015;135:1533-9.

9. Chang LC, Haggstrom AN, Drolet BA, Baselga E, Chamlin SL, Garzon MC, et al. Growth characteristics of infantile hemangiomas: implications for management. Pediatrics. 2008:122:360-7.

10. Adams DM, Trenor CC 3rd, Hammill AM, Vinks AA, Patel MN, Chaudry G, et al. Efficacy and safety of sirolimus in the treatment of complicated vascular anomalies. Pediatrics. 2016;137:e20153257.

11. Ji Y, Chen S, Li K, Xiao N, Yang X, Zheng S, et al. Measuring health-related quality of life in children with cancer living in Mainland China: feasibility, reliability and validity of the Chinese Mandarin version of PedsQL 4.0 generic core scales and 3.0 cancer module. Health Qual Life Outcomes. 2011;9:103.

12. Hao Y, Tian Q, Lu Y, Chai Y, Rao S. Psychometric properties of the Chinese version of the pediatric quality of life inventory 4.0 generic core scales. Qual Life Res. 2010:19:1229-33.

13. Varni JW, Sherman SA, Burwinkle TM, Dickinson PE, Dixon P. The PedsQL family impact module: preliminary reliability and validity. Health Qual Life Outcomes. 2004;2:55.

14. Chen R, Hao $Y$, Feng $L$, Zhang $Y$, Huang $Z$. The Chinese version of the Pediatric Quality of Life Inventory (PedsQL) family impact module: crosscultural adaptation and psychometric evaluation. Health Qual Life Outcomes. 2011;9:1-10.

15. Wang C, Shang L, Zhang Y, Tian J, Wang B, Yang X, et al. Impact of functional constipation on health-related quality of life in preschool children and their families in Xi'an, China. PLoS One. 2013;8:e77273.

16. Frommelt $P$, Juern $A$, Siegel $D$, Holland $K$, Seefeldt $M, Y u$ J, et al. Adverse events in young and preterm infants receiving topical timolol for infantile hemangioma. Pediatr Dermatol. 2016:33:405-14

17. Frost G, Relic J. Dangers of propranolol in preterm infants. Australas J Dermatol. 2013:54:237-8.

18. Lawley LP, Siegfried E, Todd JL. Propranolol treatment for hemangioma of infancy: risks and recommendations. Pediatr Dermatol. 2009;26:610-4.

19. Leaute-Labreze C, Hoeger P, Mazereeuw-Hautier J, Guibaud L, Baselga E, Posiunas $\mathrm{G}$, et al. A randomized, controlled trial of oral propranolol in infantile hemangioma. N Engl J Med. 2015;372:735-46.
20. Prey S, Voisard JJ, Delarue A, Lebbe G, Taieb A, Leaute-Labreze C, et al. Safety of propranolol therapy for severe infantile hemangioma. JAMA 2016;315:413-5

21. Haggstrom AN, Beaumont JL, Lai JS, Adams DM, Drolet BA, Frieden IJ, et al. Measuring the severity of infantile hemangiomas: instrument development and reliability. Arch Dermatol. 2012;148:197-202.

22. Janmohamed SR, van Oosterhout M, de Laat PC, van Rosmalen J, Madern GC, Oranje AP. Scoring the therapeutic effects of oral propranolol for infantile hemangioma: a prospective study comparing the Hemangioma Activity Score (HAS) with the Hemangioma Severity Scale (HSS). J Am Acad Dermatol. 2015:73:258-63.

23. Kuhlthau KA, Pulsifer MB, Yeap BY, Rivera Morales D, Delahaye J, Hill KS, et al. Prospective study of health-related quality of life for children with brain tumors treated with proton radiotherapy. J Clin Oncol. 2012;30:2079-86.

24. Varni JW, Seid M, Rode CA. The PedsQL: measurement model for the pediatric quality of life inventory. Med Care. 1999;37:126-39.

25. Orlow SJ, Isakoff MS, Blei F. Increased risk of symptomatic hemangiomas of the airway in association with cutaneous hemangiomas in a "beard" distribution. J Pediatr. 1997;131:643-6.

26. Drolet BA, Pope E, Juern AM, Sato T, Howell B, Puttgen KB, et al. Gastrointestinal bleeding in infantile hemangioma: a complication of segmental, rather than multifocal, infantile hemangiomas. J Pediatr. 2012; 160:1021-6.e3

27. Tomlinson D, Hinds PS, Bartels U, Hendershot E, Sung L. Parent reports of quality of life for pediatric patients with cancer with no realistic chance of cure. J Clin Oncol. 2011;29:639-45.

28. Bauland CG, Luning TH, Smit JM, Zeebregts CJ, Spauwen PH. Untreated hemangiomas: growth pattern and residual lesions. Plast Reconstr Surg. 2011;127:1643-8.

29. Haggstrom AN, Drolet BA, Baselga E, Chamlin SL, Garzon MC, Horii KA, et al. Prospective study of infantile hemangiomas: clinical characteristics predicting complications and treatment. Pediatrics. 2006;118:882-7.

30. Ji Y, Wang $Q$, Chen S, Xiang B, Xu Z, Li Y, et al. Oral atenolol therapy for proliferating infantile hemangioma: a prospective study. Medicine (Baltimore). 2016:95:e3908

31. Chan H, McKay C, Adams S, Wargon O. RCT of timolol maleate gel for superficial infantile hemangiomas in 5- to 24-week-olds. Pediatrics. 2013;131:e1739-47.

32. Puttgen K, Lucky A, Adams D, Pope E, McCuaig C, Powell J, et al. Topical timolol maleate treatment of infantile hemangiomas. Pediatrics. 2016;138:e20160355

33. Xu G, Lv R, Zhao Z, Huo R. Topical propranolol for treatment of superficial infantile hemangiomas. J Am Acad Dermatol. 2012;67:1210-3.

34. Ji Y, Chen $S, X u C, L i L$, Xiang B. The use of propranolol in the treatment of infantile haemangiomas: an update on potential mechanisms of action. $\mathrm{Br} J$ Dermatol. 2015:172:24-32

\section{Submit your next manuscript to BioMed Central and we will help you at every step:}

- We accept pre-submission inquiries

- Our selector tool helps you to find the most relevant journal

- We provide round the clock customer support

- Convenient online submission

- Thorough peer review

- Inclusion in PubMed and all major indexing services

- Maximum visibility for your research

Submit your manuscript at www.biomedcentral.com/submit 